\title{
GLYCEROL TRINITRATE (nitroglycerine) IN THE TREATMENT OF HEMERALOPIA (night-blindness)
}

BY

\author{
R. DE R. BARONDES, M.D.
}

SAN FRANCISCO

HEMEROLOPIA, often miscalled nyctalopia, is characterised by a difficulty in adapting or an inability to adapt the faculty of vision to faint illumination. Some of the causes ascribed to this condition are $:^{1}$

The influence of direct light of the sun during daylight, exposure, and overwork,

Nutritional deficiency (vitamin A),

Intra-ocular diseases, etc., as retinitis pigmentosa, optic atrophy, glaucoma, choroiditis. (Also included here should be mentioned arteriosclerosis, miosis, syphilis, and toxicosis such as excessive use of tobacco, coffee, and vaso-constricting drugs.)

Brain disorders,

Idiopathic and hereditary influences.

To these causes of hemeralopia should be added one other namely, a circulatory disturbance, or dysfunction, in which the retinal arteries and capillaries remain in a spastic state. This spasticity is observed to be more pronounced in those vessels in the fringe of the retina, that part of the retina having to do with vision under faint illumination. The nerve-endings in this lightperceiving area-the retinal rods-are dependent upon a proper supply of food for the regeneration of visual purple, the " night seeing agent."

As is known, visual purple is a very light sensitive substance of a rose colour, which the rods of the deepest layer of the retina are tipped with. Under normal and ordinary circumstances of bright light, visual purple bleaches to yellow, splitting off carotene during the process, and is constantly being regenerated when the eye is at rest in the dark. Visual purple is stored in the posterior portion of the cells of the pigment epithelium, and after light exposure, the pigment granules push their way inward into the processes that extend between the rods and cones, and the latter contract and shorten. These terminal organs of the optic nerve o receive the waves of light falling upon the retina, converting these $N$ vibrations into impulses which are carried by the optic nerves and $\underset{\omega}{\mathcal{N}}$ tracts to the brain where they produce the sensation of light ${ }^{2}$.

When the retinal arteries, arterioles and capillaries become 
spastic, or mildly sclerosed, as a result of disturbances of innervation, etc., these vessels are unable to carry or deliver the proper amount of blood to the nerve-endings in the light-perceiving layer of the retina. There then results a state of nutritional insufficiency to these parts and a metabolic increase of the visual purple cannot take place. Without ample regeneration, a depletion of this night-seeing agent results in a consequent poor reaction to faint illumination.

Exposure to light causes a disturbance in the metabolism of the visual purple; the more prolonged the exposure to bright light, the more rapid a depletion of this pigment. In some manner not as yet clearly understood, the retinal rods cells synthesize, utilise or " absorb" vitamin A (and perhaps the metabolic stimulant, vitamin B). Vitamin $A$ is the important factor in the regeneration of this visual purple. If sufficient vitamin A is not " absorbed" by the retinal rod cells as a result of circulatory disturbance, ample regenerations of visual purple cannot take place.

It is known that very small amounts of vitamin $A$ in the diet will relieve certain cases of functional night-blindness ${ }^{4}$. There have been many cases though of night-blindness developing in individuals whose diet contained an abundance of it. Dr. Y. Fujihira ${ }^{3}$ reported many cases of night-blindness in two Japanese regiments. Examination of the food given these soldiers convinced the medical officer that the direct cause of this disease was not the lack of vitamin $A$, but the influence of the sun during the day-time drill, and overwork.

Though the daily intake of a well-balanced diet may be adequate for the body's general needs, an insufficiency may still exist; and care should be exercised in ascribing certain diseases to nutritional deficiences when the causative factor is one of true circulatory insufficiency. As Wilbur and Eusterman state: "It is worthy of emphasis, that states of nutritional deficiency may arise, as in this case, not as a result of inadequate intake of vitamins or other foodstuff but as a result of gastro-intestinal or other disturbances " (circulatory-nutrition deficiency) " interfering with either the normal digestion and assimilation of foodstuff or their metabolic activity ${ }^{1} . "$

Hemeralopes may see normally during daylight while in bright illumination, but on approach of twilight, or on entering dimly illuminated places, have considerable difficulty in orienting themselves to this faint illumination. On suddenly coming from bright sunlight into semi-darkness, objects and dim-lights appear to take on a yellow-amber hue, and on leaving darkness to enter sunlight, cases complain of photophobia. These individuals have constricted visual fields and have considerable difficulty in seeing objects on one side while looking straight ahead. This is because the area of the 
rods in the retina not only serves for the night-vision but also the means by which objects are seen out of the direct line of vision It is this peripheral vision that enables one to become instantl conscious of moving traffic on one side or the other.

Ophthalmoscopic findings on five adult cases of hemeralopi proved most interesting. These cases presented a constricte $\mathbb{\Phi}$ blanched appearance of the peripheral portions of the retinaf arteries, and with more or less venous hyperaemia and congestion $\overrightarrow{0}$ Experiments were carried on with various vaso-dilating drugs to note their action on these spastic retinal vessels. Nitroglycerin $\overrightarrow{8}$ proved to be the most effective dilator of these although the nitrites - amyl, sodium, etc.-gave almost comparable results. It wa observed that after the adminstration of nitroglycerine $(0.003-$ $0.06 \mathrm{gm}$.), for the first few minutes, the eyes' sensitivity to faint $\mathrm{ob}_{6}^{\circ}$ jects seen from the side was less than normal. However, from fivæ to ten minutes later, the eyes' sensitivity to faint light was markedly increased, the patients having no difficulty in moving about the darkened room. In two of the subjects, the olfactory sense, an $\$$ the gustatory sense became more acute. No changes were observe in the sense of hearing, but there was a complaint at first of poop equilibrium, vertigo, throbbing in the head, etc. After the firse few doses though, these symptoms were no longer complained off $\vec{e}$

Nitroglycerine is more or less volatile, and if exposed to loses much of its strength. Coated tablets were used in the ses studies, insuring proper and accurate dosage. Care should be useds in its administration, because of its effect on the central nervous system, blood pressure, etc.

It is important to note that, if actual degenerative changes hav taken place in the walls of the arteries, such as may be found in cases of advanced arteriosclerosis where the muscle fibres have beers replaced by connective tissue, etc., nitroglycerine would be in capable of dilating such vessels, and, a night-blindness the resulp of such a condition would not be benefited by this or any othe form of therapy.

It is suggested that proper doses of the vaso-dilator drugs mighe be administered to those working more or less continuously in the dark and to whom it is especially important to be able to see in darkness, such as spies in wartime, navigators and aviators whe do night-flying ${ }^{5}$.

Curiously enough, no comprehensive study of hemeralopia and its treatment has appeared in the literature. It is odd that this fairly common condition is overlooked in the study of the eye, and its detection in an ordinary routine examination. No doubt there्E are many who suffer from night-blindness but are not aware of ito

A routine examination for night-blindness probably would reveal many more cases than are now suspected ${ }^{4}$. 
Since case records indicate that nitroglycerine and other vasodilators gave excellent results in the treatment of this condition, and, since untoward effects were absent, further trials with this method seem justified ${ }^{5}$.

\title{
BIBLIOGRAPHY
}

1. Wilbur, Dwight and Eusterman, G. B.-Nutritional night-blindness. $J l$. Amer. Med. Assoc., Vol. CII, pp. 364-366, February 3, 1934.

2. May's Manual of the Diseases of the Eye.

3. Dr. Med. Yozoh Fujihira.-Die ätiologische Betrachtung uber die spontane Nach tblindheit bei den Japanischen Soldaten. Band XII, Heft 6, Juni, 1934, Sonderabdruck aus dem Chiba Igakki, Zasshi.

4. Jeans, P. C. and Zentmire, Z.-A clinical method for determining moderate degrees of vitamin A deficiency. Jl. Amer. Med. Assoc., Vol. CII, 12, p. 892, March 24, 1934.

5. I am indebted to Dr. H. Alexander Brown, M.D., F.A.C.S., San Francisco, for his helpful co-operation and assistance in these tests; and to Drs. P. Lazoreve and $L$. Teile, Leningrad, for their articles on similar research.

\section{CATARACTA BRUNESCENS-STUDY OF THE NATURE OF THE COLOURING SUBSTANCE}

\author{
BY
}

\author{
Professor Dr. Elena Puscariu and \\ Dr. Julius nitzulescu
}

FROM THE OPHTHALMOLOGICAL CLINICS AT JASSY, ROUMANIA

DIRECTOR : PROFESSOR DR. ELENA PUSCARIU

\section{Clinical Considerations}

Cataracta Nigra (Wentzel, 1788) or more correctly named Cataracta Brunescens (Becker, 1881), because in the large majority of cases the lens presents only a more or less deep brown colour, is a rather unusual form of cataract. In our practice we have met it only four times among a total of 1,357 cases of cataract.

Some authors believe that it appears especially in myopic eyes, but only one of our four cases was short-sighted. Jess, Rollet Bussy considered that cataracta brunescens has a definitely worse prognosis than an ordinary cataract. They have frequently observed the appearance of iridocyclitis or of infections after the operation, perhaps due to the special predispositon produced by the high myopia. Our cases, just as those of Gifford and others, did not confirm this unfavourable prognosis. All four had a perfectly normal post-operative course.

Our observations can be summarised as follows:-Case 1. A peasant, aged 56 years, entered the clinic on October 19, 1925. The impairment of sight began a year previously in the left eye, 